\title{
MANIFESTOS REVERBERADOS EM UMA EDUCAÇÃO MATEMÁTICA EM PESQUISA COM CRIANÇAS: ENCONTROS E RESISTÊNCIAS NA URGÊNCIA DE SEREM PERCEBIDOS
}

\author{
MANIFESTOS REVERBERED IN MATHEMATICAL EDUCATION IN RESEARCH WITH CHILDREN: \\ MEETINGS AND RESISTANCE IN THE URGENCY OF BEING SEEN
}

\section{MANIFIESTOS REVERVERADOS EN UNA EDUCACIÓN MATEMÁTICA EM INVESTIGACIÓN CON NIÑOS: ENCUENTROS Y RESISTENCIAS EN LA URGENCIA DE SER PERCIBIDOS}

\author{
VIVIAN NANTES MUNIZ FRANCO1 \\ LUZIA APARECIDA DE SOUZA²
}

\section{RESUMO}

Este texto compõe-se de algumas borbulhas ainda ativas da dissertação de mestrado intitulada "Entre infâncias, narrativas e delírios: fora da escola, fora da matemática, fora do risco..." (2019), em que tecemos algumas aproximações entre a Educação Matemática e crianças que frequentavam a pré-escola na Educação Infantil, produzindo, com elas, narrativas, em busca de diálogos com a infância e outros encontros. Aqui, traremos alguns estilhaços dessas narrativas, revisitando algumas manifestações da infância que nos convidam a ressignificar nossas práticas, teorias e vivências, enquanto adultos, professores, pesquisadores e Educação Matemática, propondo uma conversa em torno das reverberações e estranhamentos que surgem a partir desse movimento de pesquisa. Para além disso, sinalizamos algumas preocupações teóricas e metodológicas que têm permeado nossos estudos, como as perspectivas decoloniais, no anseio e na urgência de criar espaços e possibilidades de habitar escolas e pesquisas com crianças, sendo também habitadas por elas.

Palavras-chave: Educação Matemática Infante. Pesquisa com crianças. Narrativas com crianças. Estudos decoloniais.

\section{ABSTRACT}

This text is composed of some bubbles still active in the master's thesis entitled "Between childhoods, narratives and delusions: out of school, out of mathematics, out of risk ..." (2019), in which we weave some approximations between Education Mathematics and children who attended preschool in early Childhood Education, producing narratives with them, in search of dialogues with childhood and other encounters. Here, we will bring some pieces of these narratives, revisiting some manifestations of childhood that invite us to reframe our practices, theories and experiences, as adults, teachers, researchers and Mathematics Education, proposing a conversation around the reverberations and strangeness that arise from this movement of research. In addition, we signal some theoretical and methodological concerns that have permeated our studies, such as decolonial perspectives, in the desire and urgency to create spaces and possibilities to inhabit schools and research with children, being also inhabited by them.

Keywords: Mathematical Education Infant. Research with children. Narratives with children. Decolonial studies.

\footnotetext{
1 Doutoranda no Programa de Pós-Graduação em Educação Matemática. Universidade Federal de Mato Grosso do Sul. E-mail: viviannmfranco@ gmail.com. Orcid: https://orcid.org/0000-0001-8144-0320.

2 Docente do Instituto de Matemática e do Programa de Pós-Graduação em Educação Matemática. Universidade Federal de Mato Grosso do Sul. E-mail: luapso@gmail.com. Orcid: https://orcid.org/0000-0001-8428-4503.
} 


\section{RESUMEN}

Este texto es compuesto por algunas burbujas que aún están activas de la tesis de maestría titulada "Entre la infancia, las narrativas y los delirios: fuera de la escuela, fuera de las matemáticas, fuera de riesgo ..." (2019), en la que tejemos algunas aproximaciones entre Educación Matemática y niños que asistieron a preescolar en Educación Infantil, produciendo narrativas con ellos, en busca de diálogos con la infancia y otros encuentros. Aquí traemos algunos fragmentos de estas narrativas, revisitando algunas manifestaciones de la infancia que nos invitan a replantear nuestras prácticas, teorías y vivencias, como adultos, docentes, investigadores y Educación Matemática, proponiendo una conversación en torno a las reverberaciones y extrañezas que surgen de este movimiento. de búsqueda. Además, señalaremos algunos enfoques teóricos y metodológicos que han permeado nuestros estudios, como las perspectivas descoloniales, en el deseo y urgencia de crear espacios y posibilidades para habitar escuelas e investigar con niños, siendo también habitados por ellos.

Palabras-clave: Educación Matemática Infantil. Investigación con niños. Narrativas con niños. Estudios decoloniales.

\section{UM CENÁRIO}

Pra que o nosso futuro não chore A urgência é: Precisamos ser melhores, viu? ${ }^{3}$

Pensar sobre encontros e resistências entre Educação Matemática, Educação Infantil, Anos Iniciais, crianças ou qualquer outra relação em que somos vulneráveis ao conflito, neste momento em que enfrentamos um problema de saúde pública, a Pandemia da Covid-19, pode soar supérfluo ou um subterfúgio, mas a nós, reforça uma preocupação com esse contínuo descuido com o mundo e sua diversidade, com as pessoas e suas diversidades, com os encontros e suas diversidades, com os que ainda resistem a esse projeto de dominação engendrado aos nossos modos de viver.

Este cenário reafirma como não nos queremos vulneráveis, fragilizados, assim como estamos agora diante do vírus, mas também como nos percebemos diante das crianças, da infância, mostrando todas as nossas estratégias para não colocarmos nossas identidades, crenças, teorias, metodologias e campos de pesquisa, em risco, habitando ou alimentando a ficção de que habitamos sempre nichos confortáveis e sólidos, que demandam apenas conveniências eficazes e cômodas.

Apoiadoras da criação de espaços de diálogo, aproveitamo-nos deste espaço para retomar algumas borbulhas ainda ativas da dissertação de mestrado, findada em 2019 e intitulada "Autor" de autoria da primeira autora e sob orientação da segunda, produzida junto ao Programa de Pós-Graduação em Educação Matemática da Universidade Federal de Mato Grosso do Sul. Nessa dissertação, tecemos algumas aproximações entre a Educação Matemática e as crianças da Educação Infantil ao produzir narrativas com crianças de 4 e 5 anos que frequentassem a pré-escola, buscando por diálogos com a infância e outros encontros.

Então, a partir desses encontros, traremos alguns estilhaços que nos atingiram em pesquisa, na tentativa de explicitar manifestos da infância que nos convidam a ressignificar nossas práticas, teorias e vivências enquanto adultos, professores, pesquisadores e Educação Matemática. Assim, propomos uma conversa em torno dessa aproximação entre a Educação Matemática e crianças pequenas nos contextos educacionais em que estão inseridas, uma vez que tais encontros parecem causar estranhamentos e serem permeados de muitos obstáculos.

3 Trecho da música Sementes, um projeto lançado em 2020 como parte de uma campanha contra o trabalho infantil.com interpretação e composição de Emicida e Drik Barbosa, produzido pelo Laboratório Fantasma. Disponível em: https://youtu.be/C7IOAB--I3c. Acesso em: 30 jun. 2020. 
0 que acontece quando, em meio a uma pesquisa com crianças, nosso instinto analítico começa a julgar o que é certo ou errado sem que essa perspectiva esteja operando? Assistimos a um rompimento e percebemos, atentas, que o que decorre deste rompimento é potente. E, se ressignifica uma pesquisa, uma pesquisadora, uma orientação, uma banca de qualificação ou defesa, pode também intrometer-se com a Educação Matemática.

A rigidez atribuída à matemática cria em nós uma certa dificuldade de pensar em criar outras coisas, aquele sentimento de que tudo já foi criado, descoberto e de que foram esgotadas a possibilidades de algo novo surgir dos nossos esforços. Como se criássemos um pacto para disseminar essa matemática que já está posta, que começa e acaba nela mesma tamanha sua universalidade e neutralidade. Essa impessoalidade atribuída à matemática, quando operada por meio de números, operações, gráficos e fórmulas parece não diferenciar quando dizemos, em um problema, de milhares de laranjas ou milhares de mortos pela Covid-19 em nosso país.

Há, já, discussões que sinalizam para outros modos de se pensar e fazer matemática, para sua característica contínua e processual e para sua atuação política na sociedade. Há, antes disso, inúmeras práticas matemáticas que de tão intrínsecas ao nosso cotidiano, sequer são reconhecidas como tais. É, pois, preciso exercitar o que chamaremos de estranhamento. Para isso, é preciso fabricar e reconhecer diferenças, o que pode se dar percebendo como sujeitos, discursos, materialidades são também produzidas nesse movimento. Nesse nosso exercício, optamos por ouvir crianças de 4 e 5 anos de idade. É importante fazer notar que isso não significa considerar que crianças estranhem mais e/ou melhor que adultos, o ponto que se coloca não é uma inversão na balança do que é ou tende a ser sub ou supervalorizado. 0 ponto que se coloca é 0 da escuta atenta, 0 da destruição da balança sustentada pelo binarismo criança/adulto que tem produzido o que Miranda Fricker (2007) tem chamado de injustiça epistêmica. Segundo Fricker (2007) isso ocorre quando alguém é erroneamente especificado em sua capacidade de conhecedor. A disfunção epistêmica se dá com a falta de credibilidade atribuída àquele que fala por conta da visão estereotipada produzida sobre ele. Às crianças, por exemplo, costuma serem atribuídas características como ignorantes, inocentes, ingênuas, frágeis, imaturas, incompletas...

Para começarmos a tratar o mundo expresso pelas crianças como possível, precisamos repensar nossas dinâmicas de existência, começando por nos interrogar.

Quais manifestos da infância podem se manifestar em situação de pesquisa? Como as crianças me significam em seus manifestos? Como me colocar à disposição do manifesto do outro, da infância, contra nós mesmos? Como a Educação Matemática pode se colocar à disposição do manifesto da infância, contra ela mesma? 0 que a infância nos propõe? 


\section{ENCONTROS, ESTRANHAMENTOS E RESISTÊNCIAS}

Figura 1 - Um desenho de Marina.

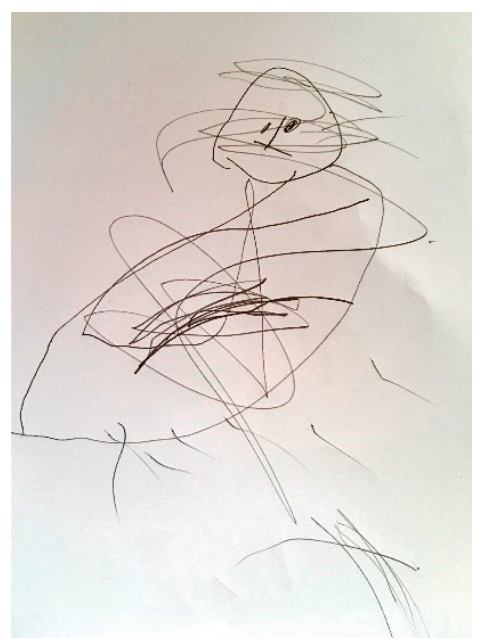

Fonte: Franco (2019, p. 48).

- Vou fazer eu. Marina, 4 anos

- Essa é você? Vivian

- Não, é eu dormindo. Marina, 4 anos

- Hum... entendi. Por que é você dormindo? Você gosta de dormir? Vivian

-... Meu, meu nariz, minha boca, minha pés e meu cabelo. Marina, 4 anos

- Isso aí é o que? Vivian

- Eu. Marina, 4 anos ${ }^{4}$

Nossos modelos prontos, roteiros, metodologias pré-estabelecidas, não dão conta do encontro com o inesperado, do estar junto, do fazer com, da leitura de um desenho, da escuta de um desenho sendo narrado.

Restringimos nossos olhares diante de imagens e seus significados e sentidos. Nesse diálogo com a Marina, é perceptível quão desconcertante é o modo como ela atribui perspectivas sobre 0 seu desenho, como vai apresentando outras possibilidades, diante das quais vamos nos perdendo.

Assim foram sendo construídos os nossos encontros em pesquisa. Entre entendimentos e desentendimentos fomos interagindo. Pesquisadoras e crianças. 0 que não é algo fácil, quando direcionamos nossas ações às crianças inventadas, aos movimentos idealizados, às normas e objetivos. Demoramos para entender que é preciso estar com elas de outras formas e que o nosso modo de vida adulto não pode estabelecer impedimentos para esse diálogo, pelo contrário, precisa se adulterar, sempre.

A infância está tão cercada pelos nossos falatórios, projetos e idealizações que é mesmo difícil se aproximar de modo efetivo e afetivo das crianças. Elas vão passando e deixando seus rastros e suas vozes, então vamos assistindo com pouca intimidade e, bruscamente, tentando capturar algo que deixe nosso querer confortável.

4 As narrativas das crianças e pesquisadora trazidas aqui, assim como as imagens, foram produzidas no desenvolvimento da pesquisa de mestrado e compõem, de outros modos, a dissertação (FRANCO, 2019), sobre a qual dedica-se este artigo. 
Essas distintas expectativas criadas em torno da infância e da criança, alimentam muitos textos e pesquisas que angustiam por tratarem de múltiplas noções e compreensões diferentes para um mesmo conceito. Talvez tratar a infância por definições, interpretações e conceitos seja importante e necessário, mas omita suas interessantes insignificâncias. Quando as atenções se voltam para a infância, na maioria das vezes, são para criar concepções e discursos com o intuito de distanciar as crianças da infância que habitam e criar condições para que elas se tornem as projeções idealizadas por nós adultos.

Em cada tempo houve (e ainda há) um conjunto de normas disciplinadoras que prescrevem o que é ser criança, como é o seu brincar, quais seus gostos, como pensa, 0 que deve saber, pensar e dizer em cada idade; e 0 que é ter infância. A criança e a infância são capturadas pelas ideias que produzimos sobre elas; criamos formas de aprisioná-las, parecendo que se pode antecipar tudo sobre elas, restando muito pouco para o inesperado e para os encontros. (CHISTÉ, 2015, p. 54 e 55).

Ao dizer que as crianças e infâncias estão cercadas pelo que nós produzimos sobre elas, sinalizamos também o distanciamento que criamos com as possibilidades desse encontro. Como então estar entre infâncias e crianças? Uma sugestão que fizemos é a de começarmos pelo desespero, nos aproximando do Manoel de Barros (2006), que diz que "o desespero é sempre o que não se espera".

Em nossa dissertação tratamos dessas provocações e efeitos que 0 trabalho foi produzindo em uma pesquisadora entre os seus desesperos, tentando explorar algumas das potencialidades que uma pesquisa com crianças nos oferece para repensarmos os modos como nos relacionamos e nos referimos a elas e à infância.

Para isso, tecemos um diálogo sobre essa maneira adultocêntrica de tratar a infância, nos aproximando mais uma vez dos poemas de Manoel de Barros (2015) que nos ajudou a ter um pouco mais de intimidade com insignificâncias e desimportâncias que feriam nossas expectativas. 0 poeta está o tempo todo com a sua infância, muitas vezes, tida por nós adultos como uma fase menor, desimportante, sem valor e deixa claro que prefere se manter distante das estruturações e idealizações do adulto.

- Mas eu não vi nada, eu não fui lá no espaço amanhã. Eu vou, eu tava indo, porque... eu tava indo, porque eu sonhei e eu fui e aí eu vi uma coba. Uma coba. E aí eu tinha medo. Francisco, 4 anos

- Você tem medo do espaço? Vivian

- Não, da coba. Francisco, 4 anos

Na maioria das vezes não compreendemos as crianças, o que elas fazem, o que é dito por elas, que mesmo com suas indescritíveis habilidades de inventar, criar, profanar e fazer de conta, suas vozes não são ouvidas, são consideradas pequenas e incompletas, como alguém que ainda não é, mas que precisa ser preparada para ser.

A verdade é que mantemos uma relação com a criança como se ela fosse uma menoridade, uma falta, um estado precário. Mas a infância não é apenas um estágio para a maturidade. É uma janela que, fechada ou aberta, permanece viva dentro de nós. (MIA COUTO, 2009, p. 55). 
Quando, de forma teimosa e insistente, busca-se por definições e significados que aprisionem a infância, fechando a janela, nos deparamos com um cenário que se apropria de uma nomenclatura para caracterizar a criança ou justificar o modo como devem ser tratadas.

A própria acepção terminológica latina de "infância", vem de in-fans, que significa sem linguagem. No interior da tradição metafísica ocidental, não ter linguagem significa não ter pensamento, não ter conhecimento, não ter racionalidade. Neste sentido, a criança é focalizada como alguém menor, alguém a ser adestrado, a ser moralizado, a ser educado. (GALZERANI, 2005, p. 56 e 57).

Somos passíveis de responder a esse significado atribuído ao termo infância com a tentativa de dar voz às crianças, muitas vezes, intuindo confrontar esse entendimento do sujeito da infância como aquele que não fala, que é incapaz, que ainda precisa ser educado, ensinado, formado. Esta é uma possibilidade.

Manoel de Barros (2013), por sua vez, sugere outro caminho. A relação da palavra infância com expressões como "sem linguagem", "sem voz" ou "aquele que não fala", não impediram que ele enxergasse e trouxesse para suas poesias as potencialidades dessa infância onde as palavras faltam.

Depois que iniciei minha ascensão para a infância,

Foi que vi como 0 adulto é sensato!

Como não ascender ainda mais até na ausência da voz?

(Ausência da voz é infantia, com t, em latim.)

Pois como não ascender até a ausência da voz -

Lá onde a gente pode ver o próprio feto do verbo -

ainda sem movimento.

Aonde a gente pode enxergar o feto dos nomes -

ainda sem penugens.

Por que não voltar a apalpar as primeiras formas

da pedra. A escutar

Os primeiros pios dos pássaros. A ver

As primeiras cores do amanhecer.

Como não voltar para onde a intenção está virgem?

Por que não ascender de volta para o tartamudo! (BARR0S, 2013, p. 380 e 381).

Não restam dúvidas ou desconfianças acerca da existência das vozes das crianças da infância, elas não só existem, como estão em toda parte, de várias formas. São barulhentas, silenciosas, divertidas, surpreendentes, inesperadas, gaguejantes... Por que não voltar a escutar? Mas, agora, nos colocando em uma escuta do que tem sido chamado de uma "experiência da linguagem",

[...] em que aquilo que se tem experiência é a própria língua. A linguagem não é feita somente do que se fala, mas também de silêncios e ausências. Portanto, uma experiência da in-fância. Infância não como lugar cronológico, mas infância em que as palavras não estão ainda presas aos modelos lógicos abstratos, ou às subjetividades fabricadas, moduladas, consumidas. (FLORES, 2017, p. 184). 
Acreditamos que para falar com a infância e pôr-se a escuta é preciso estar com ela, aproximar-se dela. Uma vez que, as concepções de infância estão relacionadas com o modo que se trata a criança e também que se estabelece uma comunicação com ela, lembremo-nos: "a criança não está em um mundo diferente do mundo dos adultos" (CHISTÉ, 2015).

Então, ao cercar-se de infâncias e crianças, como estar com elas?

Estar com as crianças é um deslocamento, mas não no sentido de sair daqui e de repente estar com elas em algum outro lugar, mas de ser, de ser com elas outras coisas, não fingindo ou encenando, mas tornando-se outras coisas ao ser afetada por elas, por seus olhares, suas vozes, suas respostas.... Tornando-se prof., tia, pesquisadora ou uma estranha.

Estabelecer diálogos com as crianças envolve encontros e desencontros de perguntas e respostas, olhares, interesses... mas são esses exercícios que nos aproximam da infância e que às vezes até nos colocam em nossas infâncias, não de um modo ingênuo, mas infantil, infante, desconstruindo modos de estar no mundo.

Figura 2 - Entre fugas 5.

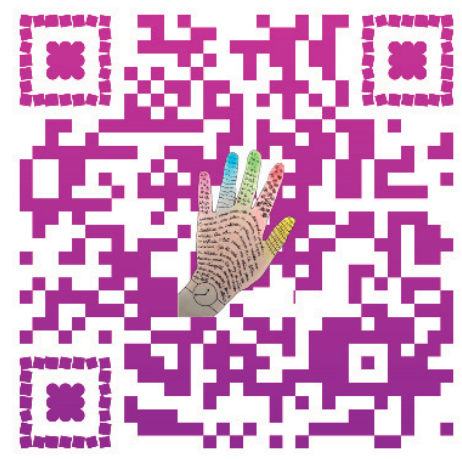

Fonte: Franco (2019, p. 48).

Apesar dos preconceitos e subestimações criados em torno da criança, que acabam alimentando uma falsa ideia de ingenuidade e falta de conhecimento, ela não é apenas um aprendiz que desconhece coisas, ela também ensina, questiona e desenvolve estratégias o tempo todo para estar com os adultos. Com isso, a criança está preparada e ansiosa para lidar não só com modos acriançados.

A criança exige dos adultos explicações claras e inteligíveis, mas não explicações infantis, e muito menos as que os adultos concebem como tais. A criança aceita perfeitamente coisas sérias, mesmo as mais abstratas e pesadas, desde que sejam honestas e espontâneas e, por isso, algo pode ser dito a favor daqueles velhos textos. (BENJAMIN, 1994, p. 236 e 237).

Por isso estar com as crianças é colocar as nossas identidades em risco, porque com elas operamos diálogos a serem interrogados e levados para os mais diversos lugares.

5 Dentre as narrativas que compuseram nosso trabalho, algumas estiveram em QR code e para acessá-las você precisará de um leitor de QR codes, que poderá ser baixado em seu aparelho celular, por exemplo. 
- Sim, eu assisti isso já. Francisco, 4 anos.

- Já assistiu? Que legal. Então Francisco, você sabe que eles moram lá no espaço, né?! Vivian.

- Eles não moram lá no espaço, eles moram aqui na casa com os humanos. Francisco, 4 anos.

- Ah, na casa com os humanos! Mas eles passeiam às vezes, né? Tem algumas pessoas que ficam lá no espaço. Vivian

- Hum. Francisco, 4 anos.

Dentre os aprendizados que acorreram nesses encontros, um em especial diz respeito a essa subestimação. É importante olhar para as muitas demonstrações que evidenciam a necessidade de repensarmos essa postura.

- E vocês escrevem o número também? Vivian.

- Aham. A gente escreve de letra cursiva já. Mario Antônio, 5 anos.

- Você quer sentar onde pra gente pintar, pode ser no sofá mesmo? Vivian

- Tem que ser onde não rasga o papel, no sofá rasga o papel. Marina, 4 anos

- Pode ser na mesa? Vivian

- Sim, na mesa. Marina, 4 anos

A aproximação com a infância por muitas vezes foi incômoda pela minha inexperiência para lidar com a desordem. E, além disso, a criança nos diz poucas e boas sobre as nossas fraquezas e limitações.

A criança possui a capacidade imaginativa aguçada e, por isso, promove 0 advento do imprevisível. E é bem verdade que o imprevisível traz certo desconforto, desacomoda-nos de nossas verdades encerradas. 0 caráter inaugural da infância coloca-nos frente ao outro, que pensa diferente, que fala diferente, que com suas perguntas intermináveis nos rouba de nossas próprias certezas, permite-nos experienciar a alteridade, a mobilização de nossas concepções estáticas. (ROSA, 2018, p. 57).

- E você sabe algum dos números além do zero e do sete? Vivian.

- 0 sete, zero. Só sei o sete e o zero. Anthonyelle, 4 anos.

- Tem um assim que você fez pra mim, né?!

Que é quanto? 0 da mãozinha... Vivian.

- Polegares, milho, não, mínimo, qual que é esse mesmo? Anthonyelle, 4 anos.

Há muito que se pensar e discutir sobre a criança, mas até aqui, nos esforçamos para estar com ela, experienciando essa mobilização de nossas concepções estáticas, nos espantando, nos desesperando. Antes de definições, perspectivas e conceitos, elas, as crianças, estão por aí, inventando, aprendendo, brincando e espacializand $0^{6}$ o mundo, das mais diversas maneiras. E sobre isso, há muito mais para se falar. E quando não tem nada para dizer, a criança faz de conta.

Sua vitalidade para fazer as coisas e explorar o espaço não condiz com a pausa reflexiva e com a olhada para trás que fazem com que os lugares pareçam saturados

6 Como este espaço vem sendo praticadolvivenciado? TUAN, 1983. 
de significância. A imaginação da criança é de um tipo especial. Está presa à atividade. Uma criança cavalga um pau como se estivesse sobre um cavalo de verdade, e defende uma cadeira virada como se fosse um verdadeiro castelo. (TUAN, 1983, p. 37).

Na infância tudo parece ser mais interessante, novo, encantador/amedrontador, então existe algo diferente nas experiências da criança. De fato! No encontro entre a criança e 0 adulto, o modo de ver o mundo, ou a "sensibilidade de mundo"7 não se diferencia apenas pela maturidade ou a falta dela, mas pelos interesses, que divergem.

Elas [as crianças] se sentem atraídas irresistivelmente pelos detritos, onde quer que eles surjam [...]. Nesses detritos, elas reconhecem o rosto que o mundo das coisas assume para elas, e só por elas. Com tais detritos, não imitam o mundo dos adultos, mas colocam os restos e resíduos em uma relação nova e original. Assim, as próprias crianças constroem seu mundo de coisas, um microcosmos no macrocosmos. (BENJAMIN, 1994, p. 237 e 238).

- Eu já fui de chinelo uma vez porque meu pé tava machucado. Maria Clara, 6 anos.

- Hum... Entendi! Vivian.

- Você foi de chinelo preto? Marina, 4 anos.

- Eu tenho... outro chinelo, que é de oncinha, não sei, mas é colorido. Maria Clara, 6 anos

Quando nos voltamos para as insignificâncias da infância são evidenciadas experiências que os conceitos e definições não dão conta de apresentar. Mas optar por trilhar caminhos desconhecidos dialogando e compondo com crianças, não pode ser complicado e, além disso, arriscado? Talvez! Porém, talvez também seja interessante, desafiador e potente caminhar com o infante e quem sabe também tornar-se aquele

que não fala tudo, não sabe tudo e nem pensa tudo, mas que pensa de novo e faz pensar de novo. É aquele que, na impossibilidade de se expressar, cria significados, recupera ideias, vasculha funcionamentos, e narra o que foi experienciado. Caminhar em direção à infância significa, portanto, re-encontrar nossa própria condição infantil. (FLORES, 2017, p. 184).

Frente aos despropósitos da infância em pesquisa, fazer uma pesquisa infantil é também fazer um esforço muito grande para buscar em nosso olhar a infância que o habita. E, nesse sentido, nosso trabalho se propos a pensar modos de pesquisas com crianças, com a infância, assim como, a construção de fontes narrativas com crianças, o que contribui para um movimento de efetivação de trabalhos com essa essa temática no âmbito do campo científico.

[...] escutar as crianças sobre suas próprias experiências e legitimar suas narrativas como fonte de pesquisa relacionam-se no campo científico a um duplo movimento de ruptura. Por um lado, quanto aos conceitos de criança e de infância, tradicionalmente dominantes. Por outro lado, quanto à validade dessas fontes para a pesquisa educacional. (PASSEGGI E ROCHA, 2012, p. 37).

7 Esta expressão é utilizada por Mignolo (2017, p. 20) e para mim, amplia as possibilidades de afetos. 
As crianças das quais nos aproximamos para realizar essa pesquisa nos ofereceram a desapresentação de uma escola da infância, de suas atividades, brincadeiras, gostos e desgostos. E não foi só sobre a escola que elas lançaram seus olhares e se expressaram, mas também sobre nós, sobre pesquisa, sobre pesquisadores, sobre perguntas, posturas, interesses e desinteresses.

- 0 que você não gosta de fazer? Vivian

- Humm... de tomar água. Anthonyelle, 4 anos.

- E você pinta por favor. Marina, 4 anos.

- Humm... E você vai fazer o que? Vivian.

- Ué, vou pintar uma coisa. Marina, 4 anos.

- E a sua sala de aula? Podia pintar ela, né?! Vivian.

- Vou pintar... vou fazer um piriquito. Marina, 4 anos.

- Um piriquito? E tem piriquito lá na escola? Vivian.

- TSC TSC... Marina, 4 anos.

- Não? Vivian.

0 encontro entre uma pesquisadora e uma criança não é despretensioso, pois não há investigação sem pretensão. Entretanto, existe um empenho em não desenvolver uma pesquisa que se sirva das crianças para vasculhar a infância em busca de vestígios que interessem, mas uma pesquisa que se dê efetivamente com a participação das crianças.

Nesse sentido, acreditamos que esse envolvimento das crianças com a pesquisa, além de permitir a compreensão dos modos como praticam a escola e se relacionam com a matemática,

[...] contribuem para superar uma visão de criança como objeto de pesquisa, [anunciando] possibilidades metodológicas para a efetivação do discurso da criança como sujeito de direitos. Trata-se aqui de pensar a escola com as crianças e não pelas crianças. (PASSEGGI Et al.,2012, p. 6, grifo das autoras)

Ao optar por desenvolver um trabalho com crianças nos expomos às consequências do despreparo, das limitações, da improvisação. Exercícios que passam a fazer parte da pesquisa e que também constituem pesquisadores. Existe uma dinâmica, uma linguagem, uma movimentação de corpos para o qual não se prepara, é algo que se constitui naquele momento, com aquela criança.

- Vamos desenhar...? Anthonyelle, 4 anos.

- Pinta minha casa... enquanto eu bebo um pouco de água.

- Pinta de colorido. Marina, 4 anos.

Para sentar com as crianças é necessária uma primeira aproximação e, na maioria das vezes, essa aproximação aconteceu em encontros que deram medo, desestabilizaram. A criança não tem interesse algum em suprir as expectativas de uma pesquisa e muito menos de pesquisadores. Talvez ela tenha curiosidade, mas não um compromisso a cumprir. 0 encontro com uma criança é 
descompromissado, não por parte dos pesquisadores, mas por parte da criança. É importante que as pesquisas tomem cuidado com essa postura equivocada, que no caso desse trabalho, seria esperar que as crianças resolvessem o nosso problema de pesquisa ${ }^{8}$.

- Ah, você podia desenhar os seus coleguinhas. Vivian

- eu não quero. Marina, 4 anos

- não? Vivian

- aí, agora é de manhã, eu não estudo de manhã. Marina, 4 anos

- hum, entendi! Você estuda a tarde? É? Vivian

- é, e meus colegas também. Marina, 4 anos

Em pesquisa nos cercamos do compromisso de explicar porque estamos ali, como estamos ali, o que estamos fazendo, como vamos usar os materiais produzidos, para a criança e os pais. Cercamo-nos de explicações de quem somos, de onde viemos, o que pretendemos, enquanto a criança não tem esse compromisso e talvez não damos conta de explicitar isso a nós mesmos. Percebemos isso pelos olhares agoniados de quem acompanhava as entrevistas em que as crianças se recusavam a falar, eram sucintas, mudavam de assunto. Elas ainda estão livres do compromisso de suprir expectativas, sanar dúvidas. E é por isso que "as coisas que não têm nome são mais pronunciadas por crianças" (BARROS, 2013, p. 276).

- Ta demorando você com essa conversa... Anthonyelle, 4 anos.

As crianças apresentaram muitas possibilidades para o que chamamos de matemática e escola. Desespero. A matemática agora são muitas coisas, são várias. Com as crianças, palavras criam asas e perdem as asas também, quando se acham muito importantes.

- A matemática é balé, é assim que faz balé. Francisco, 4 anos.

Figura 3 - Entre matemáticas.

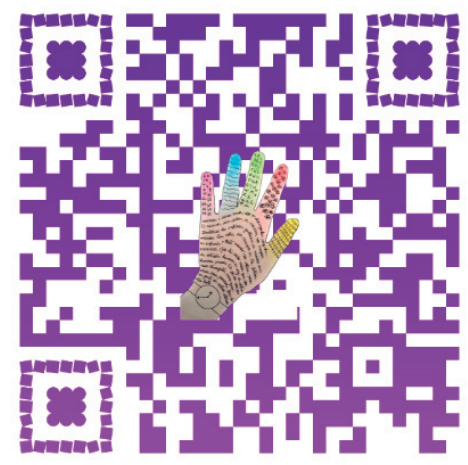

Fonte: Franco (2019, p. 48).

8 "Vamos ver como os índios resolvem nossos problemas de relação com a natureza'. E ficamos decepcionados quando vemos que os índios, primeiro, têm outros problemas e, segundo, não resolvem os nossos. [...] Portanto, só nos cabe saber quais são os problemas deles e como a relação dos problemas pode nos tirar de nossos próprios impasses, que não são os deles". (VIVEIROS DE CASTRO, 2010, p. 19). 
- Eu acho que matemática é contar os números, o abc... Maria Clara, 6 anos.

- Hum... E o que mais? Vivian.

- 0 aeiou. Marina, 4 anos.

- 0 que vocês contam lá na escola? Vivian.

- A gente conta número. Mario Antônio, 5 anos.

- Letra. Marina, 4 anos.

- Letra. Mario Antônio, 5 anos.

- Como que vocês contam letra? Vivian.

- 0 alfabeto. Maria Clara, 6 anos.

- A, B, C, D, E, ,F ,G, H, I, J, K, L, M, N, O, P, Q, R, S, T, U, V, W, X, Y, Z. Marina, 4 anos.

Nessa pesquisa, nesses registros, as crianças resistiram à essa insana busca por respostas para perguntas e expectativas de uma pesquisadora, que contrariavam inclusive nossos discursos teóricos e metodológicos. Ao olhar para as nossas conversas e para as as intervenções, não só ficam destacadas as falas que surgem das crianças, mas também está em xeque uma postura pesquisadora, em um encontro ambicioso.

- Você gosta de fazer tarefa ou não muito? Vivian.

- Não muito, eu só gosto um pouquinho. De vez em quando eu canso a minha mão quando eu faço tarefa. Anthonyelle, 4 anos.

0 que é isso que você desenhou?

É igual que vocês fazem na escola?

Ou na escola é diferente? Vivian.

Na escola é diferente. Marina, 4 anos.

Por que? Vivian.

Porque não pode sair fora do risco. Marina, 4 anos.

- E tem mais alguma coisa da sua escola que você lembra pra falar? Ela é grande, pequena? Vivian.

- Tem flores... Anthonyelle, 4 anos.

- Tem flores! Vivian.

Tem flores! Que escolas são essas manifestadas pelas crianças? Que matemáticas são essas? Como acolhemos essas manifestações? Apesar das provocações é inerente às crianças manifestarem seus gostos, desgostos, ideias, medos, sons, gestos, já a nós, restou uma escuta que precisa ser afinada para que sejamos afetados e façamos reverberar em nossas práticas a potência dessas narrativas. 


\section{DA URGÊNCIA DE CRIAÇÃO DE ESPAÇOS E POSSIBILIDADES}

Figura 4 - Parquinho.

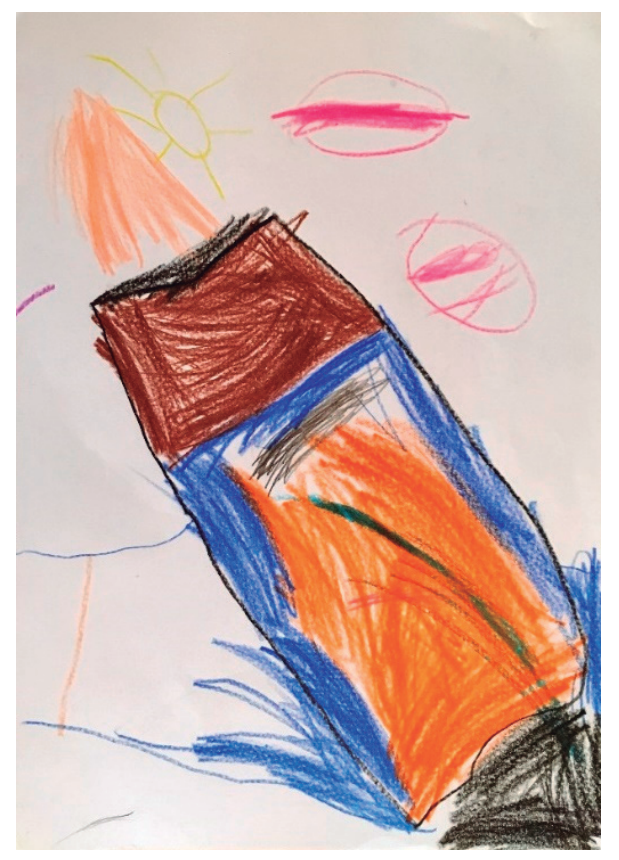

Fonte: Franco (2019, p. 48).

As crianças nos apresentam outras escolas possíveis, outras matemáticas possíveis, outras percepções, outras referências, mas continuamos, enquanto Educação Matemática e pesquisa, supondo crianças, supondo interesses, supondo corpos em nossas ações. Por isso, precisamos racionalizar a intenção e, compreendendo-a, abandoná-la. Passamos, então, a tensionar no contexto de pesquisas com crianças, pensar exercícios de criação de espaços e possibilidades, no âmbito teórico e metodológico, junto delas, arejando nossos modos de fazer, os espaços que ocupamos, nossos sentidos, buscando por outros caminhos.

Pensar em um caminho infante, talvez nos coloque em uma primeira proposta de deslocamento, uma vez que "a infância é a condição de ser afetado que nos acompanha a vida toda. 0 dito e 0 não-dito, a falta de palavra, a ausência de voz (in-fans), nos afetos. É aquela singularidade silenciada que não pode ser assimilada pelo sistema" (KOHAN, 2003, p. 239). Além disso, compartilhamos do pensamento de Mia Couto (2009), quando diz que

A infância não é um tempo, não é uma idade, uma colecção de memórias. A infância é quando ainda não é demasiado tarde. É quando estamos disponíveis para nos surpreendermos, para nos deixarmos encantar. Quase tudo se adquire nesse tempo em que aprendemos o próprio sentimento do Tempo. (COUTO, 2009, p. 55).

A provocação é convidativa, mas o desafio é nos aproximarmos de práticas tão estranhas a nós. Por isso, esse se mostra um caminho longo a ser percorrido. É indispensável à Educação Matemática 
se perceber como lugar de pesquisa, de ética, de estética, de política, mas também de criança, a ser praticada pela infância. Do mesmo modo, à pesquisa, e ao pesquisador que a conduz, adulto que é, convém uma revisão do olhar, uma busca por outro lugar de se fazer, de dialogar.

Aprender com as crianças, outras coisas, para além do conhecimento já institucionalizado, pode ser um modo de escapar, ou ainda, de ir na contramão dos discursos já postos e dominantes.

Dar-se conta da alteridade infantil no desenrolar da pesquisa é fazer aparecer sua presença e junto com ela compor as aberturas necessárias ao já sabido, ao já dito, ao já consolidado. Do mesmo modo, dar às crianças a oportunidade de confrontar-se com experiências com os adultos, que não sendo necessariamente pedagógicas (mas educativas, pois transformam) reativem nossas capacidades criadoras de outros mundos, menos temerosos no exercício de dizer 'e se fosse de outro modo?' (COSTA et al., 2015, p. 31).

Então, que princípios teóricos fundamentam ou devem fundamentar um campo de estudo sobre infâncias, em Educação Matemática, nas direções que estamos propondo? Como estabelecer interações de qualidade entre crianças e adultos e junto a isso constituir uma produção teórica, metodológica e analítica plausíveis, comprometidas e atentas às urgências dos campos de conhecimento envolvidos?

Uma possibilidade talvez seja a de não abandonar essas interrogações durante qualquer trajetória de pesquisa. Para mais, ainda optando por alternativas mais amplas, buscamos sempre por interrogações filosóficas, infantes ou suscetíveis a elas.

0 que as pesquisas e discussões em que já estamos inseridas nos permitem afirmar são as nossas posturas dominadoras sobre a criança da infância. Assim, assumimos, de antemão, que a matemática, a pesquisa e 0 adulto pesquisador têm atitudes de dominação e controle sobre a infância. Essa é a luta atual a qual nos propomos, contra essas práticas que se manifestam como dinâmicas da colonialidade (QUIJANO, 2005; MIGNOLO, 2017; SANTOS, 2019; SPIVAK et al, 2010, entre outras obras e autores) em nossas relações com as crianças, contra os apagamentos e silenciamentos que construímos e impomos a elas.

Por colonialidade, junto aos autores já citados, entendemos os processos de subalternização e dominação de determinados grupos, suas práticas e subjetividades, que se sustenta ainda hoje, mesmo com o fim do colonialismo territorial, que precede e fundamenta a origem da colonialidade ${ }^{9}$. Assim, os estudos decoloniais, com os quais se relacionam nossos interesses, dizem de um vasto movimento teórico, constituído por diferentes grupos, que tecem críticas à colonialidade e problematizam seus diferentes aspectos, em uma busca por combatê-los.

Por isso, os estudos decoloniais, junto às Epistemologias do Sul, e suas lutas contra os mais diversos apagamentos, contribuem conosco em mais de uma direção. No sentido de fornecer elementos que nos ajudem a decolonizar nossos olhares sobre a infância, mas também, o da possibilidade de a criança fundamentar um processo de descolonização do nosso modo de estar no mundo.

\footnotetext{
9 Dentro das perspectivas dos autores que produzem estudos em torno da colonialidade, há algumas divergências quanto aos termos empregados. Para Santos (2019), por exemplo, "[...] A colonialidade é, em verdade, a continuação do colonialismo por outros meios, um outro tipo de colonialismo. Por essa razão eu prefiro continuar a falar de colonialismo para caracterizar o que Quijano chama de colonialidade, uma vez que não há nenhuma razão analítica para reduzir o colonialismo ao tipo específico que foi o colonialismo histórico caracterizado pela ocupação territorial por potência estrangeira". Entretanto, acreditamos que 0 intuito não seja 0 de concentrar-nos em tais comparações e diferenciações, mas de também se colocar nesse exercício decolonial de explora novos modos de produção e atribuição de significados mais peculiares.
} 
As epistemologias do Sul referem-se à produção e à validação de conhecimentos ancorados nas experiências de resistência de todos os grupos sociais que têm sido sistematicamente vítimas da injustiça, da opressão e da destruição causadas pelo capitalismo, pelo colonialismo e pelo patriarcado. Chamo 0 vasto e muito diverso âmbito dessas experiências de Sul anti-imperial. Trata-se de um Sul epistemológico, não-geográfico, composto por muitos suis epistemológicos que têm em comum 0 fato de serem conhecimentos nascidos em lutas contra o capitalismo, 0 colonialismo e o patriarcado. São produzidos onde quer que ocorram essas lutas, tanto no norte geográfico como no sul geográfico. 0 objetivo das epistemologias do Sul é permitir que os grupos sociais oprimidos representem o mundo como seu e nos seus próprios termos, pois apenas desse modo serão capazes de 0 transformar de acordo com as suas próprias aspirações. (SANTOS, 2019, p. 17)

Diante deste exercício da opção decolonial marcado por novas premissas epistêmicas, nos movimentamos para aprimorar os instrumentos de registros, sistematização e análises de experiências vivenciadas junto aos nossos interlocutores, que nesse espaço, diz-se da criança.

Nessa direção, o "pesquisar com" se mostra uma importante iniciativa nesse percurso, junto de novas abordagens, do diálogo entre os campos de saberes que participam dessa recusa de um projeto de dominação, de opções de diálogos críticos e criativos junto aos conflitos disciplinares e institucionais dos quais não podemos escapar e da criação de espaços de interrogação e de interrogadores dessa relação.

Nesse sentido, as epistemologias do Sul desafiam as epistemologias dominantes em dois níveis diferentes. Por um lado, consideram crucial a tarefa de identificar e discutir a validade de conhecimentos e de modos de saber não reconhecidos como tal pelas epistemologias dominantes. Concentram-se, dessa forma, em conhecimentos "inexistentes", assim considerados pelo fato de não serem produzidos de acordo com metodologias aceitáveis, ou mesmo inteligíveis, ou porque são produzidos por sujeitos "ausentes", sujeitos concebidos como incapazes de produzir conhecimento válido devido à sua impreparação ou mesmo à sua condição não plenamente humana. (SANTOS, 2019, p. 19)

Além disso, quando Boaventura (2019) compõe a discussão teórica da qual temos nos aproximado com a afirmação de que "todo conhecimento é corpóreo" e junto disso, no âmbito da Educação Matemática, nos encontramos com os estudos do corpo mobilizados por Sinclair e Freitas (2019; 2014), percebemos 0 quanto essa problematização do corpo não pode estar ausente, visto que 0 corpo é o mediador dessas relações que temos buscado estabelecer.

As epistemologias do Sul tratam de conhecimentos que estão presentes na resistência e na luta contra a opressão ou que delas surgem, conhecimentos que são, por isso, materializados, corporizados em corpos concretos, coletivos ou individuais. Esse caráter corpóreo do conhecimento coloca muitos desafios. (SANTOS, 2019, p. 135)

[...] 0 corpo é importante de forma significativa em todas as questões sobre saber, ser, aprender e avaliar - especialmente quando adotamos posturas não dualistas. Estamos ansiosos para ver novas perguntas de pesquisa e novos experimentos 
metodológicos que nutrem ainda mais essa aproximação entre diferentes áreas do conhecimento. ${ }^{10}$ (SINCLAIR e FREITAS, 2019, p. 234, tradução nossa).

Precisamos ainda nos inteirar desses mecanismos e forças exercidas aos corpos diferentes, que importam de maneiras diferentes, como colocado por Sinclair e Freitas (2019), assim como, de práticas e posturas coniventes com os projetos colonizadores, também caracterizados pelos autores decoloniais.

A partir dessas ideias que vão nos encontrando, nos provocamos a pensar sobre essa matemática que praticamos, ainda que teoricamente, e como ela se apresenta como um dispositivo da colonialidade e também como um desdobramento do corpo, uma vez que indagamos a possibilidade de se fazer matemática sem corpo, um corpo, aliás, a ser educado pela matemática, ou em prol dela. E, com isso, nos colocamos a pensar na relevância do corpo na Educação Matemática e a razão decolonial dessa problematização.

E aqui, um outro espaço a ser criado, é o da legitimação desses saberes que os esforços anteriores estimulam a serem produzidos. Nos colocando a pensar como 0 conhecimento em produção está sendo/será exposto, ou ainda, como o conhecimento construído pela infância está sendo julgado. Pois, se nós nos movimentamos para criar condições de possibilidades para que um conhecimento seja produzido, mas ignoramos esse conhecimento, ou tratamos esse conhecimento como algo inferior, ou ainda de modo comparativo, continuamos exercendo uma dinâmica colonizadora.

Assim, Fricker (2007), ao tratar do conceito de "Injustiça Epistêmica", contribui com nossos estudos ao inaugurar e fundamentar teoricamente a preocupação com essa injustiça que permeia alguns saberes enunciados, principalmente, a partir de estereótipos preconceituosos, julgamentos de credibilidade e também, pelo que a autora enuncia como preconceitos de identidade, nem sempre implícitos nas relações e que na teorização vão adquirindo especificações e elucidações com as quais ainda estamos construindo intimidade, para então pensarmos movimentos de desprendimentos desses modos de nos relacionarmos, que também demandam uma urgência de serem repensados.

E dentro dos estudos decoloniais, nos aproximamos das perspectivas pós-humanistas, que ainda não se mostram efetivamente nessa escrita, mas se apresentam pós-coloniais e podem nos oferecer novas provocações e interrogações, ou, mais uma vez, interrogadores dessa relação que estamos construindo com a infância e suas demandas, principalmente quanto a esse nosso interesse dos estudos do corpo da criança na Educação Matemática, na produção matemática e de outros conhecimentos.

Desta forma, sinalizamos alguns dos caminhos pelos quais enxergamos a possibilidade de um dia, ao falarmos de escola, ou pensarmos nela, possa se desenhar em nossa cabeça um parquinho com areia e um rio e, não mais, ou não apenas, carteiras, lousa, filas, paredes e números, sem cores, sem corpos e sem vida.

\section{MANIFESTO FINAL}

Que Educação Matemática, precisamos nos perguntar, temos criado?

0 que uma pesquisa em Educação Matemática cria? Inventa? Pode?

Nada? Não, não é possível.

10 [...] the body matters significantly in all questions about know- ing, being, learning and valuing-especially when we adopt non-dualistic stances. We are eager to see new research ques- tions and new methodological experiments that further nour- ish this cross-fertilisation. 
Nós temos criado e inventado muitas coisas, e é importante continuarmos com inauguramentos em pesquisa em Educação Matemática e com todas as suas potências éticas, estéticas e políticas. Políticas? Sim, é importante, sempre, considerar se a pesquisa que se produz é inclusiva ou excludente.

Multiplicidade importa. Diferença importa. Importa também...

... nos colocar mais interrogações filosóficas e infantes.

... construir outros significados.

... explorar o mundo expresso pelas crianças, pois são mundos possíveis.

... reinventar nossos sentidos para criar uma dinâmica espontânea e não impositiva para habitar esse mundo infante presente.

... reencontrar outros modos para lidar com o mundo, com os quais já perdemos intimidade.

... assim como as crianças, assustar a normalidade, apavorar o que está posto.

... parar de deslegitimar a fala da criança.

... entender que elas estão brincando sim e que isso é sério.

... entender que seus corpos dizem, e sabem o que e do que estão dizendo e fazendo.

... aceitar que rabiscos e silêncios são linguagens.

... parar jogar ao vento as sugestões da infância.

... reconhecer nossa participação na Educação matemática.

... nos perguntar constantemente:

Qual a matemática do brincar?

0 que é falar de matemática?

Qual o encantamento do número?

Qual o gosto da matemática?

Qual a cor da matemática?

Que som a matemática emite?

Que imagem se desenha na minha mente quando eu estou falando de matemática?

Importa também fazer perguntas mais urgentes.

Importa nos expor.

Educação Matemática...

... fabricada na prática, no levar para fora, para o quintal, para a brincadeira, sem pressa.

É importante estarmos disponíveis para respeitar, promover e contribuir com a produção de conhecimento, não apenas classificar, selecionar e excluir.

É importante estarmos disponíveis.

É importante aprender a escutar o que não é dito.

É importante produzir afetos.

É importante buscar possibilidades para além dos projetos hegemônicos, excludentes e elitizados de produção de conhecimento.

É importante não apenas compartilhar resultados e números, mas também encantamentos, aprendimentos, esquecimentos, erros, conversas, medos.

É importante nos colocar em luta, anunciar e nos aproximar, isso é inadiável.

Não façamos matemática sem humanidade, sem intimidade, sem novidade!

Vamos repetir, repetir... até ficar diferente (BARROS, 2013), até percebermos que perdemos a tirania e nos aproximamos de uma matemática viva, disponível, acessível e sensível.

Desaprender oito horas por dia ensina os princípios.

(BARROS, 2013, p. 275). 


\section{REFERÊNCIAS}

BARROS, Manoel de. Memórias inventadas: a segunda infância. Planeta, 2006.

BARROS, Manoel de. Poesia Completa. São Paulo: Leya, 2013.

BARROS, Manoel de. Meu quintal é maior do que o mundo. Rio de Janeiro: Objetiva, 2015.

BENJAMIN, Walter. Magia e técnica, arte e política: ensaios sobre literatura e história da cultura - Obras escolhidas I. São Paulo: Brasiliense, 1994.

CASTRO, Eduardo Viveiros de. 0 Anti-Narciso: lugar e função da antropologia no mundo contemporâneo. Revista brasileira de Psicanálise, São Paulo, v. 44, n. 4, p. 15-26, 2010.

CHISTÉ, Bianca Santos. Devir - criança da matemática: experiências educativas infantis imagéticas. 2015. 106 p. Tese de Doutorado - Universidade Estadual Paulista, Instituto de Geociências e Ciências Exatas, Rio Claro, 2015.

COSTA, Maria de Fátima Vasconcelos da et al. Entre escuta e saberes das crianças no imaginário da pesquisa: deslocamentos teóricos-metodológicos para o reencantamento do mundo. In: Seminário Internacional sobre Infâncias e Pós-Colonialismo, 2, 2015, Campinas. Anais do II Seminário Internacional sobre Infâncias e PósColonialismo: pesquisas em busca de pedagogias descolonizadoras. Campinas-SP: FE/UNICAMP: GEPEDISC linha Culturas Infantis, 2015.

COUTO, Mia. E se Obama fosse africano. Editora Companhia das Letras, 2009.

FLORES, Cláudia Regina. In-fante e profanação do dispositivo da aprendizagem matemática. Perspectivas da Educação Matemática - INMA/UFMS - v. 10, n. 22, seção temática, p. 171-188, 2017.

FRANCO, Vivian Nantes Muniz. Entre infâncias, narrativas e delírios: fora da escola, fora da matemática, fora do risco... 2019. 187 f. Dissertação (Mestrado em Educação Matemática) - Instituto de Matemática, Universidade Federal de Mato Grosso do Sul, Campo Grande, 2019.

FREITAS, Elizabeth de; SINCLAIR, Nathalie. Mathematics and the body: material entanglements in the classroom. New York NY: Cambridge University Press, 2014. (Learning in doing: social, cognitive, and computational perspectives).

FRICKER, Miranda. Epistemic injustice: power and the ethics of knowing. Oxford ; New York: Oxford University Press, 2007.

GALZERANI, Maria Carolina Bovério. Imagens entrecruzadas de infância e de produção de conhecimento em Walter Benjamin. In: FARIA, Ana Lúcia Goulart de; DEMARTINI, Zeila de Brito Fabri; PRAD0, Patrícia Dias (Orgs.). Por uma cultura da infância: metodologias de pesquisa com crianças. $2^{a}$ ed. Campinas, SP: Autores Associados, 2005, p. 49-68.

KOHAN, Walter Omar. Infância: Entre filosofia e educação. Belo Horizonte: Autêntica, 2003.

MIGNOL0, Walter. Desafios decolonais hoje. Revista Epistemologias do Sul, v. 1, n. 1, p. 12-32, 2017. 
PASSEGGI, Maria da Conceição et al. 0 que contam as crianças sobre as escolas da infância: aportes teóricos sobre as narrativas na pesquisa com crianças. In: Encontro Nacional de Didática e Práticas de Ensino - ENDIPE, 16., 2012, Campinas. Políticas de formação inicial e continuada de professores. Araraquara: Junqueira\&Marin Editores, 2012.

PASSEGGI, Maria da Conceição; ROCHA, Simone Maria da. A pesquisa educacional com crianças: um estudo a partir de suas arrativas sobre 0 acolhimento em ambiente hospitalar. Revista Educação em Questão, v. 44, n. 30, 2012.

QUIJANO, Anibal. Colonialidade do poder, Eurocentrismo e América Latina. In: LANDER, Edgardo et al. (Ed.). A colonialidade do saber: eurocentrismo e ciências sociais. Perspectivas latino-americanas. Buenos Aires: CLACSO, Consejo Latinoamericano de Ciencias Sociales, p. 117-142, 2005.

ROSA, Glenda Matias de Oliveira. No descomeço era o verbo: Manoel de Barros e a roda de conversa na educação infantil. 1. Ed. Curitiba: Appris, 2018.

SANTOS, Boaventura de Sousa. 0 fim do império cognitivo: a afirmação das epistemologias do sul. [S.l: s.n.], 2019.

SINCLAIR, Nathalie; FREITAS, Elizabeth de. Body studies in mathematics education: diverse scales of mattering. ZDM, v. 51, n. 2, p. 227-237, maio 2019.

SPIVAK, Gayatri Chakravorty et al. Pode o subalterno falar? Belo Horizonte: Editora UFMG, 2010.

TUAN, Yi Fu. Espaço e lugar: a perspectiva da experiência. São Paulo: DIFEL, 1983.

RECEBIDO EM: 30 jun. 2020

CONCLUÍDO EM: 02 out. 2020 
